\title{
Role of peripheral phenanthroline groups in the self-assembly of self-assembled molecular triangles
}

\author{
MILI C NARANTHATTA, V RAMKUMAR and DILLIP KUMAR CHAND* \\ Department of Chemistry, Indian Institute of Technology Madras, Chennai 600 036, India \\ e-mail:dillip@iitm.ac.in; dillipiitm@gmail.com
}

MS received 18 September 2014; accepted 30 September 2014

\begin{abstract}
Self-assembled molecular triangles $\left[\mathrm{Pd}_{3}(\text { phen })_{3}(\text { imidazolate })_{3}\right]\left(\mathrm{NO}_{3}\right)_{3}$, 1a and $\left[\mathrm{Pd}_{3}(\text { phen })_{3}\right.$ (imidazolate $\left.)_{3}\right]\left(\mathrm{PF}_{6}\right)_{3}, \mathbf{1 b}$ are prepared by the combination of imidazole with $\mathrm{Pd}(\mathrm{phen})\left(\mathrm{NO}_{3}\right)_{2}$ and $\mathrm{Pd}(\mathrm{phen})$ $\left(\mathrm{PF}_{6}\right)_{2}$, respectively. Imidazole was deprotonated during the complexation reactions and the imidazolate so formed acted as a bis-monodentate bridging ligand to form the bowl-shaped trinuclear architectures of $\mathbf{1 a} / \mathbf{b}$. Relative orientation of the imidazolate moieties can be best described as syn,anti,anti as observed in the crystal structure of $\mathbf{1 b}$. However, in solution state, slow conformational changes are assumed on the basis of ${ }^{1} \mathrm{HNMR}$ spectral data. The molecular triangles are crafted with three peripheral phen units capable of $\pi-\pi$ stacking interactions. Well-fashioned intermolecular $\pi-\pi$ interactions are observed in the solid-state, wherein further self-assembly of already self-assembled triangle is observed.
\end{abstract}

Keywords. Palladium(II); 1,10-phenanthroline; imidazole; self-assembly; molecular triangle.

\section{Introduction}

The design and construction of discrete molecular architectures through metal-directed self-assembly have undergone significant development in recent years. ${ }^{1}$ These techniques involve self-assembly of multidentate ligands and chosen metal ions to afford infinite or finite self-assembled molecules. The understanding and utilization of all non-covalent interactions including hydrogen bonding ${ }^{2}$ or $\pi-\pi$ stacking $^{3}$ is of fundamental importance for further development of crystal engineering besides the synthesis of new self-assembled molecules. These weak intermolecular interactions contribute largely to the supramolecular association in the solid state.

The structural advantage of the square-planar coordination environment of palladium(II) has been generally utilized for the construction of molecular architectures by this approach. ${ }^{1 \mathrm{a}-\mathrm{f}}$ Designed discrete structures are known to be achieved from the combination of a variety of palladium(II) components and appropriate ligand. When a cis-protected palladium(II) component is treated with suitable bis-monodentate ligand $\mathbf{L}$, it provides self-assembly having formula $\left[\mathrm{Pd}_{\mathrm{x}}\left(\mathrm{L}^{\prime}\right)_{\mathrm{x}}(\mathbf{L})_{\mathrm{y}}\right](\text { monoanion })_{2 \mathrm{x}}$ where $\mathrm{L}^{\prime}$ is the cis-protecting unit. ${ }^{1 \mathrm{a}-\mathrm{f}}$ cis-Protection has been carried out by using simple bidentate chelating ligands

*For correspondence such as ethylenediamine (en), 2,2'-bipyridine (bpy), tetramethylethylenediamine (tmeda), 1,10- phenanthroline (phen), etc.

Although there are reports on several designed palladium(II)-based coordination cage molecules,,${ }^{1 \mathrm{a}-\mathrm{f}}$ various aspects of their chemistry related to crystal engineering are less explored. ${ }^{4}$ We have been investigating the roles of the motifs present in cis-protecting units to conceptualize targeted packing of self-assembled coordination compounds in the solid state. We have reported certain binuclear self-assembled coordination cages, designed for pre-defined intermolecular interactions in solid state to direct further self-assembly of the already self-assembled coordination cages. ${ }^{4 a-b}$ The $\pi-\pi$ stacking is the targeted intermolecular interactions in our designs. Thus, we have demonstrated a pre-defined packing in the crystal structure of 'opened jaws' type and 'steps type' complexes and considered this kind of packing as 'self-assembly of selfassembly. ${ }^{4 a-b}$ This novel packing behaviour of the already self-assembled molecules are obtained due to the presence of $\pi$-surfaces at the strategically located cis-protecting moieties located around the palladium(II) centres.

The self-assembly of self-assembly approach has been recently extended by us to trinuclear palladium(II) complexes. ${ }^{5}$ Unfortunately, there are only a limited number of studies on trinuclear complexes having formula $\left[\mathrm{Pd}_{\mathrm{x}}\left(\mathrm{L}^{\prime}\right)_{\mathrm{x}}(\mathbf{L})_{\mathrm{y}}\right](\text { monoanion })_{2 \mathrm{x}}$ that are prepared from palladium(II) and bis-monodentate 
ligands. ${ }^{1 \mathrm{a}-\mathrm{f5}-7}$ Further, the trinuclear complexes usually exist in dynamic equilibrium with corresponding bi/tetra-nuclear complexes. ${ }^{7}$ However, there are a few studies where the trinuclear complexes are solely isolated as single discrete products. Despite the above mentioned limitation, we have reported a rare variety of self-assembled molecular triangle $\left.\left[\mathrm{Pd}_{3}(\text { bpy })_{3} \text { (imidazolate) }\right)_{3}\right]\left(\mathrm{NO}_{3}\right)_{3}$, (figure 1a) having syn, syn, syn relative orientation of the bound imidazolate moieties in the solid state. ${ }^{5}$ Further self-assembly of the self-assembled molecular triangle is demonstrated in the solid state, wherein a linear propagation is observed utilizing intermolecular $\pi-\pi$ interactions (figure 1c). ${ }^{5}$ This self-assembly of self-assembly is guided by $\pi-\pi$ stacking interactions due to the presence of a $\pi$-surface in the bpy units which is the cis-protecting moiety around the palladium(II) centers.

We have prepared a modified version of the above mentioned trinuclear complex by incorporating phen units as cis-protecting moiety around the palladium(II) centers instead of bpy (scheme 1). The modification was undertaken so as to explore the consequence of the presence of extended $\pi$-surfaces on the crystal packing. It was anticipated that the judicial introduction of extended $\pi$-surfaces in cis-protecting units at the corners of a triangular architecture should give rise to specific packing via $\pi-\pi$ stacking interactions. Interestingly, relative orientation of the bound imidazolate moieties in the studied complex in the solid state is found to be syn, anti, anti. During this study, we observed linear chain-like arrangement of the molecules by using all the three phen units as shown in figure 1d. This observation is in contrast to the linear arrangement of triangular panels where only two out of the three bpy units are used in a given chain. This observation demonstrates the influence and importance of subtle change in $\pi$-surface on the crystal engineering aspects of the molecular triangles.
(4)

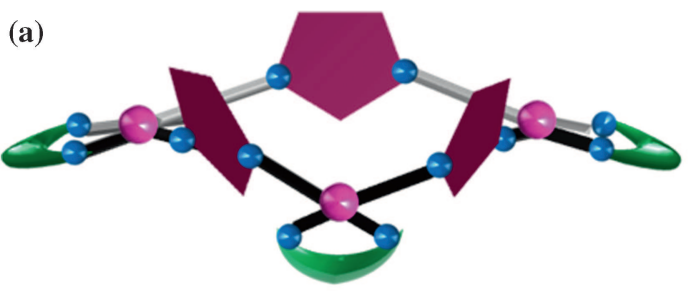

(b)

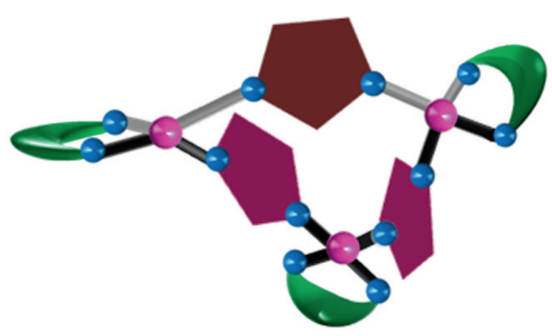

(c)

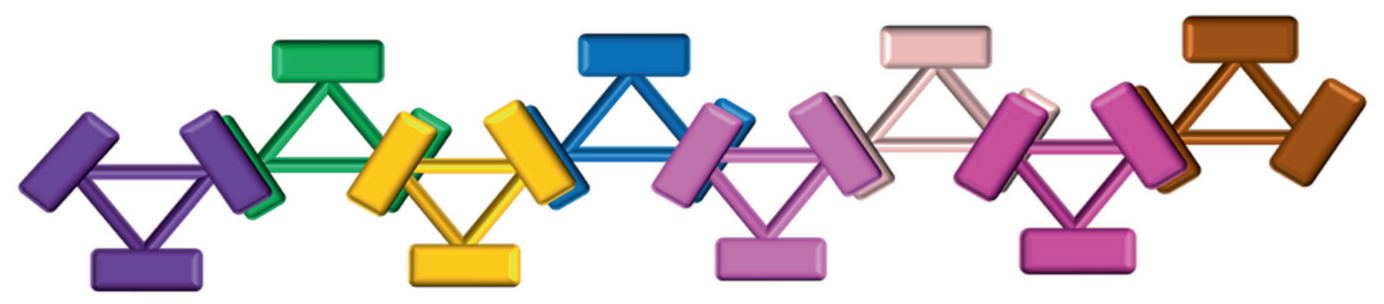

(d)

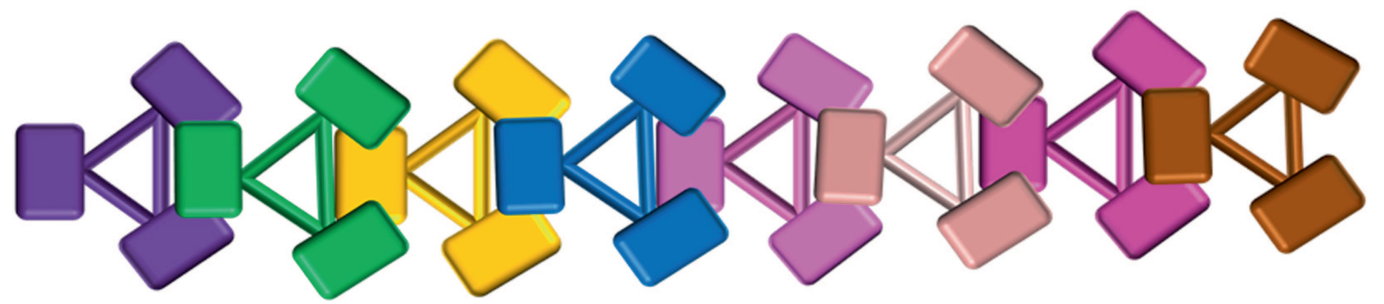

Figure 1. Cartoon diagram showing the relative orientation of the bound imidazolate units in the trinuclear complexes (a) syn, syn, syn-form in $\left[\mathrm{Pd}_{3}(\text { bpy })_{3}(\text { imidazolate })_{3}\right]\left(\mathrm{NO}_{3}\right)_{3}$ (reference 5); and (b) syn, anti, antiform in $\left[\mathrm{Pd}_{3} \text { (phen }\right)_{3}$ (imidazolate $\left.)_{3}\right]\left(\mathrm{NO}_{3} / \mathrm{PF}_{6}\right)_{3}, \mathbf{1 a} / \mathbf{b}$. Cartoon diagram of self-assembly of self-assembled molecular triangles using $\pi-\pi$ stacking interactions in $\left.(\mathbf{c})\left[\mathrm{Pd}_{3}(\mathrm{bpy})_{3} \text { (imidazolate }\right)_{3}\right]\left(\mathrm{NO}_{3}\right)_{3}$ (reference 5); and $(\mathbf{d})\left[\mathrm{Pd}_{3}(\text { phen })_{3}(\text { imidazolate })_{3}\right]\left(\mathrm{PF}_{6}\right)_{3}$, 1b. (Each triangular unit in $(\mathbf{c}) /(\mathbf{d})$ represents the core of the trinuclear molecules.) 


\section{Experimental}

\subsection{Materials}

$\mathrm{PdCl}_{2}$ was obtained from Aldrich, whereas $\mathrm{AgNO}_{3}$, $\mathrm{AgPF}_{6}$, imidazole $(\mathbf{L} \cdot \mathbf{H})$ and all the common solvents were obtained from Spectrochem, India. The deuterated solvent (DMSO- $d_{6}$ ) was obtained from Aldrich and Cambridge Isotope Laboratories. ${ }^{1} \mathrm{H}$ and all NMR spectral data were obtained from a Bruker $500 \mathrm{MHz}$ FT NMR spectrometer using external Tetramethylsilane (TMS) in $\mathrm{CDCl}_{3}$ as reference. The mass spectra were obtained from a Micromass Q-TOF Mass Spectrometer. The crystal structure was determined using a Bruker X8 Kappa XRD instrument. The cis-protected palladium(II) component was obtained following wellknown processes. ${ }^{8}$ Imidazole was used as such for complexation without any purification.

\subsection{Synthesis of $\left.\left[\mathrm{Pd}_{3}(\text { phen })_{3} \text { (imidazolate }\right)_{3}\right]\left(\mathrm{NO}_{3}\right)_{3}$, $1 a$}

To a solution of $\mathrm{Pd}(\mathrm{phen})\left(\mathrm{NO}_{3}\right)_{2}$ (11.0 mg, 0.028 $\mathrm{mmol})$ in $1: 1$ acetonitrile-water $(2.8 \mathrm{~mL})$, imidazole, $\mathbf{L} \cdot \mathbf{H}$ (1.93 $\mathrm{mg}, 0.028 \mathrm{mmol}$ ) was added and the mixture was stirred at room temperature for $2 \mathrm{~h}$. The resulting solution was evaporated by standing at room temperature and dried under vacuum to afford a white solid as the product. Yield: $(90 \%)$. M.P.: $230^{\circ} \mathrm{C} .{ }^{1} \mathrm{H}$ NMR $(\delta 500$ MHz, DMSO- $d_{6}$, external $\mathrm{CDCl}_{3} / \mathrm{TMS}$ ): 9.68 (d, $J=$ $\left.10.5 \mathrm{~Hz}, 2 \mathrm{H}, \mathrm{H}_{\mathrm{c}}\right), 9.1\left(\mathrm{~d}, J=6 \mathrm{~Hz}, 2 \mathrm{H}, \mathrm{H}_{\mathrm{a}}\right), 8.98(\mathrm{~s}$, $2 \mathrm{H}, \mathrm{H}_{\mathrm{d}}$ ), 8.72-8.69 ( $\left.\mathrm{m}, 2 \mathrm{H}, \mathrm{H}_{\mathrm{b}}\right), 8.1-7.5$ (broad signals, $2 \mathrm{H}, \mathrm{H}_{\mathrm{f}}$ ); ESI-MS: $m / z=353$ corresponding to $\left[1-3 \mathrm{NO}_{3}\right]^{3+}$ and 560 corresponding to $\left[1-2 \mathrm{NO}_{3}\right]^{2+}$.

\subsection{Synthesis of $\left[P d_{3}(\text { phen })_{3}(\text { imidazolate })_{3}\right]\left(P F_{6}\right)_{3}$, $1 b$}

To a solution of $\mathrm{Pd}(\mathrm{phen}) \mathrm{Cl}_{2}(11 \mathrm{mg}, 0.03 \mathrm{mmol})$ in $1: 1$ acetonitrile-water $(3 \mathrm{~mL})$, silver hexafluorophosphate was added (15.5 mg, $00.06 \mathrm{mmol})$, which led to immediate precipitation of $\mathrm{AgCl}$. The resulting mixture was heated for $30 \mathrm{~min}$ and centrifuged. The yellow colour solution of $\mathrm{Pd}(\mathrm{phen})\left(\mathrm{PF}_{6}\right)_{2}$ so formed was separated by filtration. To the clear yellow solution, ligand $\mathbf{L} \cdot \mathbf{H}(2$ $\mathrm{mg}, 0.03 \mathrm{mmol}$ ) was added and the mixture was stirred at room temperature for about $2 \mathrm{~h}$. The resulting solution was evaporated by standing at room temperature and dried under vacuum to afford a yellow solid as the product. Yield: (90\%) M.P.: $120^{\circ} \mathrm{C}$ (decomposed). ${ }^{1} \mathrm{H}$ NMR ( $\delta 500 \mathrm{MHz}, \mathrm{DMSO}-d_{6}$, external $\left.\mathrm{CDCl}_{3} / \mathrm{TMS}\right)$ : $9.67\left(\mathrm{~d}, J=9 \mathrm{~Hz}, 2 \mathrm{H}, \mathrm{H}_{\mathrm{c}}\right), 9.1(\mathrm{~d}, J=6.5 \mathrm{~Hz}, 2 \mathrm{H}$, $\left.\mathrm{H}_{\mathrm{a}}\right), 8.97\left(\mathrm{~s}, 2 \mathrm{H}, \mathrm{H}_{\mathrm{d}}\right), 8.72-8.70\left(\mathrm{~m}, 2 \mathrm{H}, \mathrm{H}_{\mathrm{b}}\right), 8.13-$ 7.93 (broad signals, $2 \mathrm{H}, \mathrm{H}_{\mathrm{f}}$ ); ESI-MS: $m / z=353$ corresponding to $\left[\mathbf{1 b}-3 \mathrm{PF}_{6}\right]^{3+}$ and 601 corresponding to $\left[\mathbf{1 b}-2 \mathrm{PF}_{6}\right]^{2+}$. Single crystals of $\mathbf{1 b}$ were obtained by slow diffusion of carbon tetrachloride into solution of $\mathbf{1 b}$ in acetonitrile-water.

\subsection{Single crystal $X$-ray diffraction}

X-ray data were collected with a Bruker AXS Kappa Apex II CCD diffractometer equipped with graphite monochromated $\operatorname{Mo}(\mathrm{K} \alpha)(\lambda=0.7107 \AA$ ) radiation. Crystal fixed at the tip of the glass fibre was mounted on the goniometer head and was optically centered. The automatic cell determination routine, with 32 frames at three different orientations of the detector was employed to collect reflections and the program APEX2-SAINT (Bruker 2004) was used to find the unit cell parameters. Four-fold redundancy per reflection was utilized for achieving good absorption correction using a multiscan procedure. Besides absorption, Lorentz polarization and decay correction were applied during data reduction. The program SADABS was used for absorption correction using the multiscan procedure. The structures were solved by direct methods using SHELXL 2013 (Sheldrick 2013) ${ }^{9}$ and refined by full-matrix least-squares techniques using SIR92 (WinGiX) computer program. All hydrogen

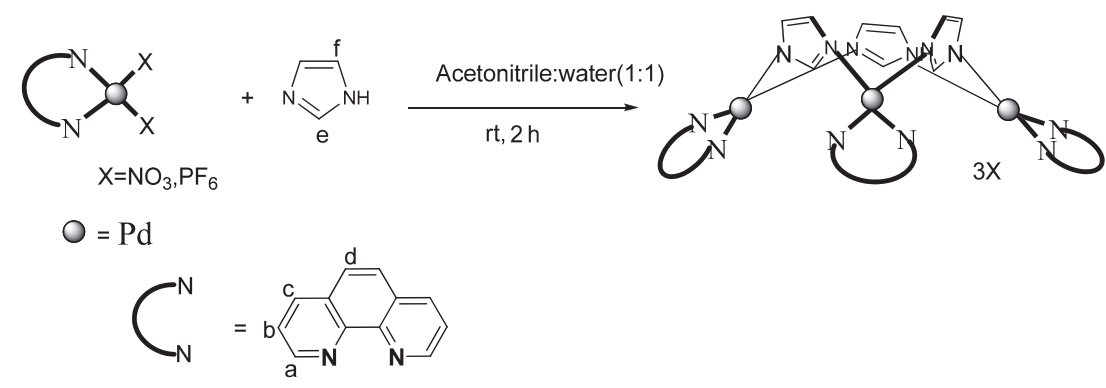

Scheme 1. Synthesis of the self-assembled trinuclear complexes $\left[\mathrm{Pd}(\text { phen })_{3}(\text { imidazolate })_{3}\right](\mathrm{X})_{3}, \mathbf{1 a} / \mathbf{b}\left(\mathrm{X}=\mathrm{NO}_{3}, \mathbf{1 a} ; \mathrm{PF}_{6}, \mathbf{1 b}\right)$. 
atoms were fixed at chemically meaningful positions and riding model refinement was applied. Molecular graphics were generated using Mercury programs. The crystal data with refinement details are summarized in table 1.

\section{Results and Discussion}

Imidazolate is a bent bis-monodentate bridging ligand which upon complexation with right-angled cis-protected palladium(II) component, i.e., $\mathrm{Pd}(\mathrm{phen})\left(\mathrm{NO}_{3}\right)_{2}$, should yield a cyclic bowl type cage with spontaneous deprotonation of imidazole (L.H). Pyrazolate or substituted imidazolate bridged complexes are reported with this type of deprotonation processes. ${ }^{6 a, b, 10}$ Imidazole groups can be orientated either in a syn, syn, syn (cone conformer $^{6 \mathrm{a}-\mathrm{c}}$ or syn, anti, anti (alternate conformer) $)^{11}$ fashion in the cages. Based on this idea, we have recently reported a bowl-shaped trinuclear molecule, $\left[\mathrm{Pd}_{3}(\text { bpy })_{3}(\text { imidazolate })_{3}\right]\left(\mathrm{NO}_{3}\right)_{3}$ and investigated the possible intermolecular interactions among such bowls in which the $\pi$-surface containing cis-protecting unit such as bpy was crafted around the palladium(II). ${ }^{5}$ In order to compare the influence of the $\pi$-surface area

Table 1. Crystallographic data and structure refinement parameters of 1b (CCDC No 990213).

\begin{tabular}{lc}
\hline Empirical formula & $\mathrm{C}_{47} \mathrm{H}_{36} \mathrm{~F}_{18} \mathrm{~N}_{13} \mathrm{P}_{3} \mathrm{Pd}_{3}$ \\
\hline Formula weight & 1537.00 \\
Crystal system & Orthorhombic \\
Space group & $\mathrm{P} \mathrm{n} \mathrm{m} \mathrm{a}$ \\
$a(\AA)$ & $27.4761(5)$ \\
$b(\AA)$ & $22.2198(4)$ \\
$c(\AA)$ & $8.8846(2)$ \\
$\alpha\left(^{\circ}\right)$ & 90 \\
$\beta\left({ }^{\circ}\right)$ & 90 \\
$\gamma\left({ }^{\circ}\right)$ & 90 \\
Volume $(\AA)^{3}$ & $5424.17(18)$ \\
$\mathrm{Z}$ & 4 \\
Wavelength $(\AA)$ & 0.71073 \\
Temperature $(\mathrm{K})$ & $296(2)$ \\
Calculated density $\left(\mathrm{g} / \mathrm{cm}^{3}\right)$ & 1.882 \\
Absorption coefficient $\left(\mathrm{mm}{ }^{-1}\right)$ & 1.184 \\
$\mathrm{~F}(000)$ & 3016 \\
Crystal dimensions $(\mathrm{mm})^{3}$ & $0.380 \times 0.150 \times 0.100$ \\
$\theta$ min/max $($ deg $)$ & $1.74 / 24.99$ \\
Reflections collected/unique & $68547 / 4923[\mathrm{R}(\mathrm{int})=0.0416]$ \\
Data/restraints/parameters & $4923 / 0 / 392$ \\
Goodness-of-fit on $F^{\wedge} 2$ & 1.052 \\
Final $R$ indices $[\mathrm{I}>2$ sigma(I)] & $\mathrm{R} 1=0.0395, \mathrm{wR} 2=0.1039$ \\
$R$ indices (all data) & $\mathrm{R} 1=0.0511, \mathrm{wR} 2=0.1140$ \\
Largest difference & 1.067 and -0.784 \\
peak and hole $(\AA)^{-3}$ & \\
\hline & \\
\hline &
\end{tabular}

located at the strategic position on the crystal packing, the $c i s$-protecting unit with extended $\pi$-surface such as phen was considered to craft around the palladium(II). Phenanthroline units have extended aromatic ring system which could possibly make a difference in the $\pi-\pi$ stacking when compared to bpy units. ${ }^{3}$ The reaction of cis- $\mathrm{Pd}(\mathrm{phen})(\mathrm{X})_{2}$ with one equivalent of imidazole, $\mathbf{L} \cdot \mathbf{H}$ in acetonitrile: water $(1: 1)$ at room temperature over a period of $2 \mathrm{~h}$ lead to the formation of $\left[\operatorname{Pd}(\text { phen })_{3}(\text { imidazolate })_{3}\right](\mathrm{X})_{3}, \mathbf{1 a} / \mathbf{b}$ (scheme 1). A fascinating intermolecular association in the solid state was observed for $\left.\left[\mathrm{Pd}(\text { phen })_{3} \text { (imidazolate }\right)_{3}\right]\left(\mathrm{PF}_{6}\right)_{3}, \mathbf{1 b}$ as shown in figure $1 \mathrm{~d}$ and discussed in a later section. We observed the trinuclear cages with syn, anti, anti-form (alternate conformer). To the best of our understanding, this is a rare example where a imidazolate-bridged trinuclear palladium(II) complex is isolated in syn, anti, anti-conformation. However, a benzimidazolate-bridged trinuclear platinum(II) complex with syn, anti, anti-conformation is known. ${ }^{11}$ Analysis of the crystal structures of cages 1b shows $\pi-\pi$ stacking interactions between planar phen units as anticipated. The complex $\mathbf{1 b}$ displays the packing where triangular molecules are arranged in a linear sequence via $\pi-\pi$ stacking interactions as shown in figure 1d. A detailed description of the synthesis of the complexes and crystal structures is discussed below.

\subsection{Synthesis and characterization of the $M_{3} L_{3}^{\prime} L_{3}$ self-assembly}

The complexes $\mathbf{1} \mathbf{a} / \mathbf{b}$ are prepared by the combination of equimolar quantities of the ligand $\mathbf{L} \cdot \mathbf{H}$ and cis$\operatorname{Pd}($ phen $)(\mathrm{X})_{2}$ in acetonitrile-water (1:1) at room temperature (scheme 1). Trinuclear complexes of formula $\left.\left[\operatorname{Pd}(\text { phen })_{3} \text { (imidazolate }\right)_{3}\right](\mathrm{X})_{3}$, were isolated in a quantitative manner. The trinuclear complexes are characterized by ${ }^{1} \mathrm{H}$ NMR, $\mathrm{H}-\mathrm{H}$ COSY and electrospray ionization mass spectrometry (ESI-MS) (see supporting information). Molecular structure of the complex 1b was also confirmed by single crystal XRD method. The ${ }^{1} \mathrm{H}$ NMR spectra of the complex 1a (figure 2) and 1b have been recorded in DMSO- $d_{6}$. The signals of the protons present in the phen units are observed at expected positions. The imidazolate protons designated as $\mathrm{H}_{\mathrm{f}}$ appeared as broad signals spanning a range of $0.62 \mathrm{ppm}$. However, the protons designated as $\mathrm{H}_{\mathrm{e}}$ are probably merged inside the other signals. The NMR data indicate a slow conformational movement in the solution state due to the possibility of formation of syn, syn, syn and syn, anti, anti conformers and other intermediates. The same behaviour was observed in solution 
state for the recently reported bowl-shaped complex $\left.\left[\mathrm{Pd}_{3}(\text { bpy })_{3} \text { (imidazolate }\right)_{3}\right]\left(\mathrm{NO}_{3}\right)_{3}$; which clearly shows that it occurs due to the peculiarity of imidazole rings to flip into different conformers in solution state. ${ }^{5}$ Formation of the trinuclear complex in the solution state was confirmed from ESI-MS data of the complex. The mass spectrum of $1 \mathbf{a}$ shows peaks at $\mathrm{m} / z=353$ and 560 corresponding to $\left[\mathbf{1 a}-3 \mathrm{NO}_{3}\right]^{3+}$ and $\left[\mathbf{1 a}-2 \mathrm{NO}_{3}\right]^{2+}$, respectively. The mass spectrum of $\mathbf{1 b}$ shows peaks at $m / z=353$ and 601 corresponding to $\left[\mathbf{1 b}-3 \mathrm{PF}_{6}\right]^{3+}$ and $\left[\mathbf{1 b}-2 \mathrm{PF}_{6}\right]^{2+}$, respectively.

\subsection{Crystal structure of $\left[P d_{3}(\text { phen })_{3}(\boldsymbol{L})_{3}\right]\left(P F_{6}\right)_{3}, \mathbf{I b}$}

Single crystals suitable for X-ray analysis were obtained by slow diffusion of carbon tetrachloride into solution of $\mathbf{1 b}$ in acetonitrile-water. The complex crystallized in orthorhombic space group Pnma. The structure contains $\left[\mathrm{Pd}(\text { phen })_{3}(\text { imidazolate })_{3}\right]^{3+}$ cations, three hexafluorophosphate ions and one acetonitrile molecule. Two different views of the crystal structures of the complexed cation are shown in figure 3. Coordination geometry around the metal centres and the related bond lengths and bond angles in the structure are found to be in the expected range. The bound imidazolate units are orientated in syn, anti, anti manner in the complexed cation of $\mathbf{1 b}$ Analysis of the crystal structure revealed several intermolecular interactions. Apparently, the $\pi$-surface of the cis-protecting group along with the relative conformation of the bound imidazolate groups controlled the intermolecular interactions, which is discussed in the next section. The crystallographic parameters of $\mathbf{1 b}$ are listed in table 1 .

The imaginary plane created by the three palladium(II) centres in the complex is considered as the reference plane of the molecular triangle. The three $\mathrm{Pd}$ atoms form an almost equilateral triangle with $\mathrm{Pd}-\mathrm{Pd}$ non-bonded distances of 5.95, 5.95 and $6.01 \AA$. The dihedral angles between bound imidazolate $\mathbf{L}$ and the triangular-Pd plane are $70.60,70.60$ and $73.95^{\circ}$. The dihedral angles between 'phen' plane and the reference plane are $16.28,16.28$ and $17.05^{\circ}$. The $\mathrm{C} 2$ carbon of the one of the bound imidazolate moieties is pointed opposite to the $\mathrm{C} 2$ carbons of the other two bound imidazolate moieties. Thus, the overall geometry deviates from our previously reported bowl-shaped molecule having bpy units as cis-protecting agent.

The packing of the molecular triangles in the crystal structure of $\mathbf{1 b}$ is shown in figure 4 . Two selected

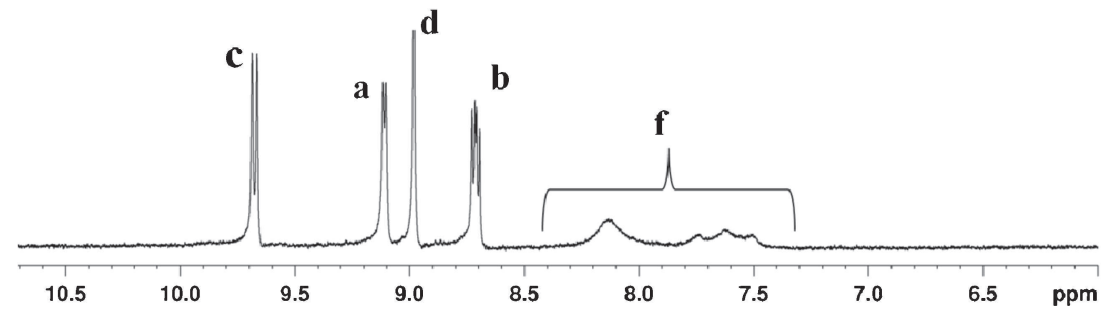

Figure 2. $500 \mathrm{MHz}{ }^{1} \mathrm{H}$ NMR spectrum in DMSO- $d_{6}$ (TMS as external standard) for $\left[\mathrm{Pd}_{3} \text { (phen }\right)_{3}$ (imidazolate $\left.)_{3}\right]\left(\mathrm{NO}_{3}\right)_{3}$, $\mathbf{1 a}$ (see supplementary information for the ${ }^{1} \mathrm{H}$ NMR of $\left.\mathbf{1 b}\right)$.

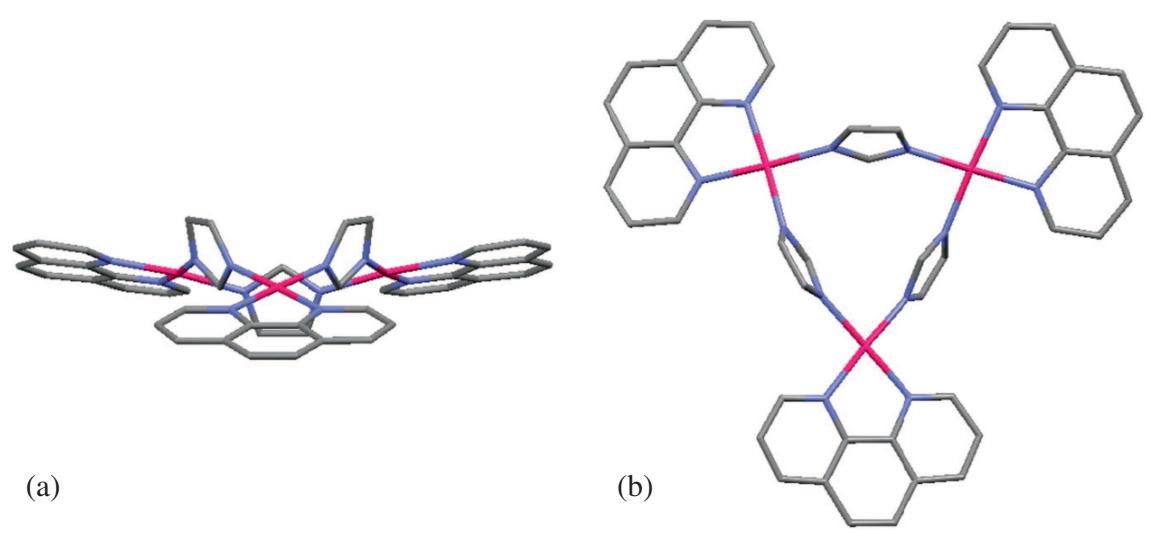

Figure 3. Crystal structure of the trinuclear complex 1b. Views along the axis: (a) parallel and (b) perpendicular to the imaginary triangle created by joining the three metal centres. 
portions from the packing are also shown in figures 5 and 6 for a better description. Adjacent molecules in the packing are associated with each other by intermolecular $\pi-\pi$ stacking interactions where one triangular unit of $\mathbf{1 b}$ is stacked with four other molecules. A given molecule interacts with two molecules along $a$-axes and two other molecules along a direction somewhat diagonal between the $b$ - and $c$-axes. As shown in figure 5, along the $a$-axis, face-to-face overlap of the phen units is observed in a linear manner where one phen unit of a triangle overlaps two phen units of the adjacent triangle. In a linear chain, each molecular triangle possesses interaction with two other triangles. The linear chains are stacked along the $c$-axis; however, they are separated by the solvent molecules, that is, acetonitrile. Figure 6 depicts the packing along a direction somewhat diagonal to the $b$ - and $c$-axes. Both edge-to-face and face-to-face overlaps are seen in this direction.

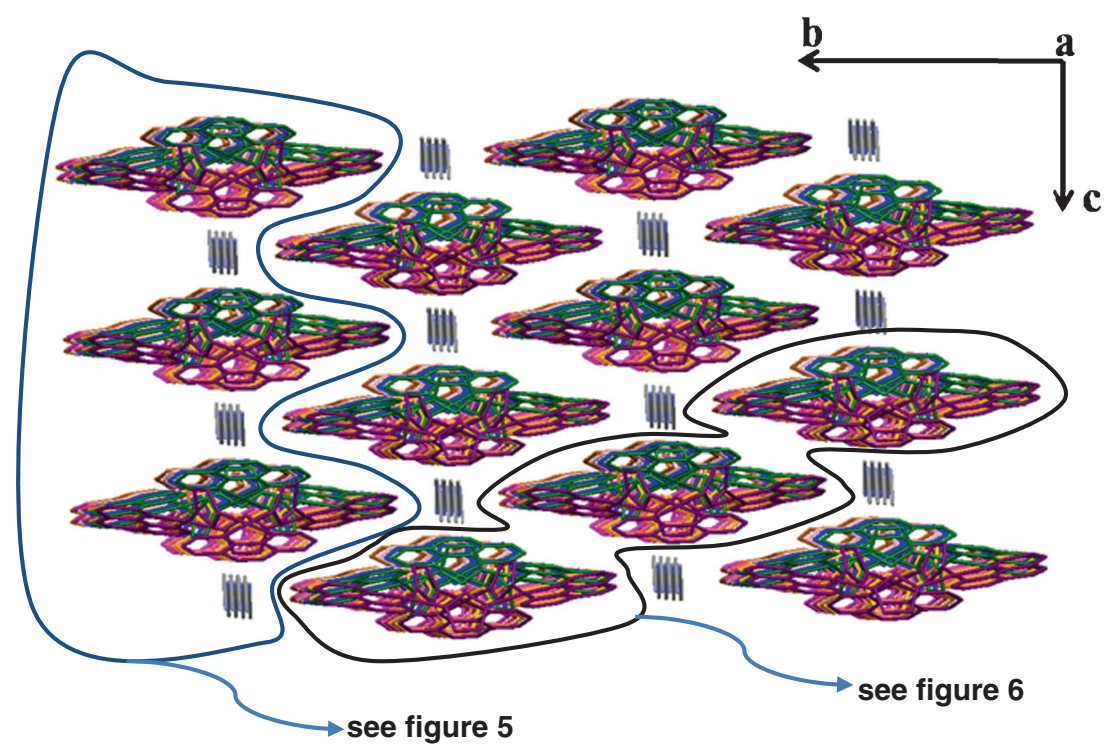

Figure 4. Packing of the molecules in the crystal structure of $\mathbf{1 b}$, in capped stick model (hydrogen atom and anions are not shown).
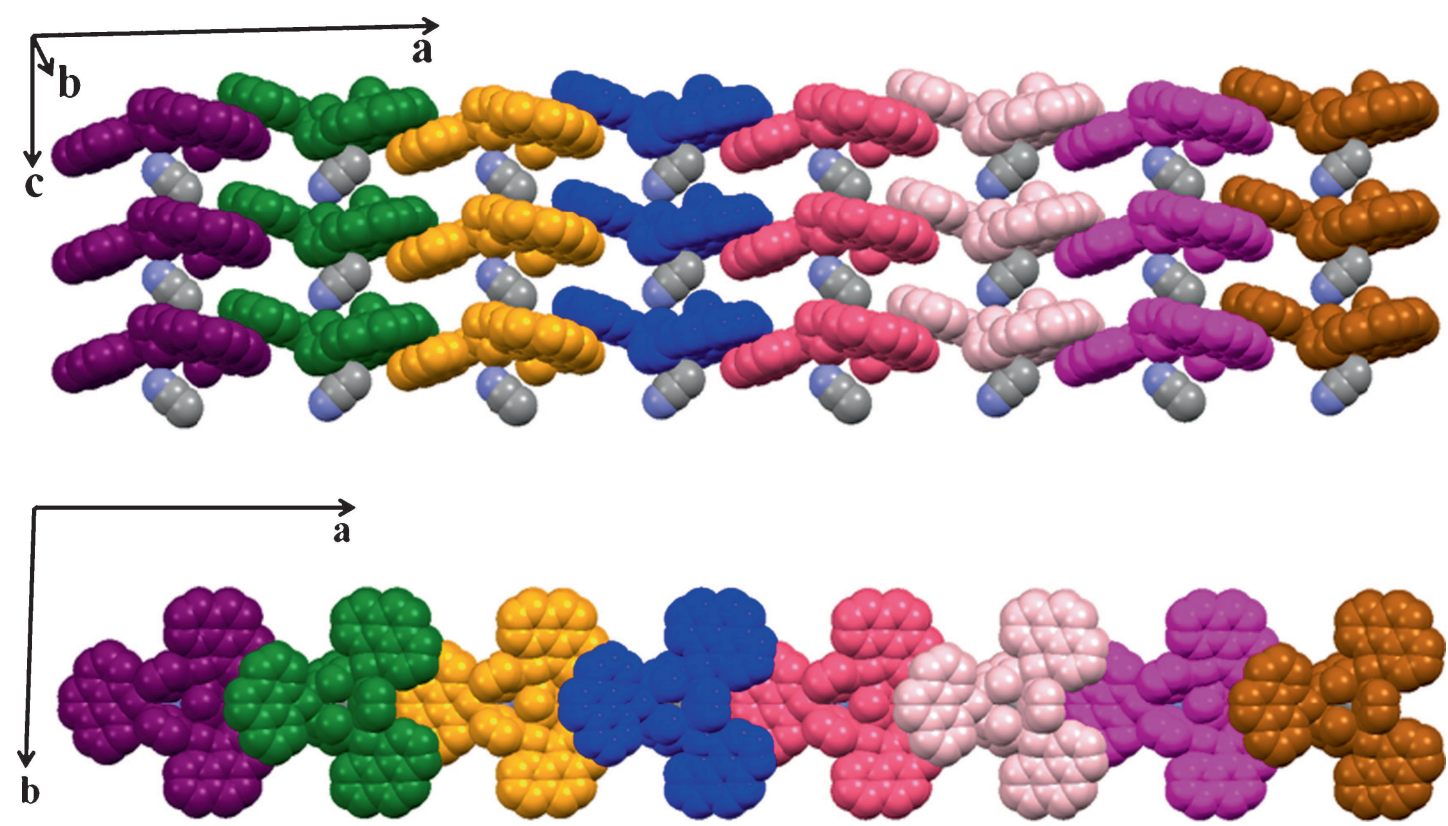

Figure 5. Packing of the molecules in the crystal structure of $\mathbf{1 b}$, in spacefill model. One of the encircled portions of figure 4 is shown in two different orientations. 


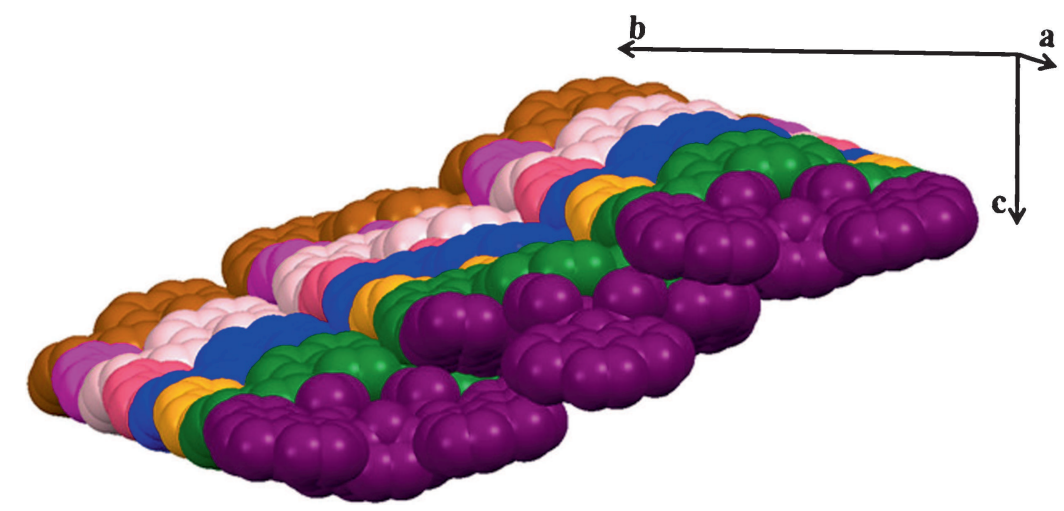

Figure 6. Packing of the molecules in the crystal structure of $\mathbf{1 b}$, one of the encircled portions of figure 4.

\section{Conclusion}

Molecular triangles are prepared using cis protected palladium(II) components as the metal fragments and imidazole as the ligand. Relative orientation of the bound imidazolate units is observed in the rare syn, anti, anti-form of a triangle in the solid state. The presence of the extended $\pi$-surface in the cis-protecting group, that is, the phen units displayed significant influence on the packing of palladium(II)-based self-assemblies in the solid state as demonstrated and compared with analogues molecule with bpy as the cis-protecting agent.

\section{Supplementary Information}

The ${ }^{1} \mathrm{H}$ NMR, H-H COSY, ESI-MS spectra are provided (figures S1-S9). X-ray crystallographic data in CIF format for the structure of $\mathbf{1 b}$ are also included. For details, see www.ias.ac.in/chemsci.

\section{Acknowledgements}

We thank DST, India (Project No. SB/S1/IC-05/2014) for financial support. We acknowledge the single crystal X-ray Diffractometer facility funded by IIT Madras.

\section{References}

1. (a)Yoshizawa M and Klosterman J K 2014 Chem. Soc. Rev. 43 1885; (b) Han M, Engelhard D M and Clever G H 2014 Chem. Soc. Rev. 43 1848; (c) Cook T R, Zheng Y-R and Stang P J 2013 Chem. Rev. 113 734; (d) Debata N B, Tripathy D and Chand D K 2012 Coord. Chem. Rev. 256 1831; (e) Fujita M, Tominaga M, Hori A and Therrien B 2005 Acc. Chem. Res. 38 371; (f) Northrop B H, Zheng Y-R, Chi K-W and Stang P J 2009 Acc. Chem. Res. 42 1554; (g) Smulders M M J, Riddell I A, Browne C and Nitschke J R 2013 Chem. Soc. Rev. 42 1728; (h) Thanasekaran P, Lee C-H and Lu K-L 2014 Coord. Chem.
Rev. 280 96; (i) Teo P and Hor A T S 2011 Coord. Chem. Rev. 255273

2. (a) Desiraju G R 2000 J. Chem. Soc., Dalton Trans. 3745; (b) Desiraju G R 2011 Cryst. Growth Des. 11 896; (c) Beatty A M 2003 Coord. Chem. Rev. 246131

3. Janiak C 2000 J. Chem. Soc., Dalton Trans. 3885

4. (a) Naranthatta M C, Das D, Tripathy D, Sahoo H S, Ramkumar V and Chand D K 2012 Cryst. Growth Des. 12 6012; (b) Tripathy D, Ramkumar V and Chand D K 2013 Cryst. Growth Des. 13 3763; (c) Krishna Kumar D, Das Amitava and Dastidar P 2006 Cryst. Growth Des. 6 216; (d) Navarro J A R, Romero M A and Salas J M 1997 J. Chem. Soc., Dalton Trans. 1001

5. Naranthatta M C, Ramkumar V and Chand D K 2014 J. Chem. Sci. 1261493

6. (a) Liu L-X, Huang H-P, Li X, Sun Q-F, Sun C-R, Li Y-Z and Yu S-Y 2008 Dalton Trans. 1544; (b) Ning G-H, Xie T-Z, Pan Y-J, Li Y-Z, Yu S-Y 2010 Dalton Trans. 39 3203; (c) Yu S-Y, Huang H, Liu H.-B, Chen Z-N, Zhang R and Fujita M 2003 Angew. Chem., Int. Ed. 42 686; (d) Tzeng B-C, Kuo J-H, Lee Y-C and Lee G-H 2008 Inorg. Chim. Acta 361 2515;(e) Qin Z, Jennings M C and Puddephatt R J 2001Chem. Commun. 2676; (f) Ghosh S, Turner D R, Batten S R.and Mukherjee P S, 2007 Dalton Trans. 1869; (g) Li S-H, Huang H-P, Yu S-Y, Li Y-Z, Huang H, Sei Y and Yamaguchi K 2005 Dalton Trans. 2346; (h) Qin Z, Jennings M C and Puddephatt R J 2002 Inorg. Chem. 41 3967; (i) Teo P, Koh L L, Hor T S A 2008 Inorg. Chem. 47 6464; (j) Bar A K, Chakrabarty R, Chi K-W, Batten S R and Mukherjee P S 2009 Dalton Trans. 3222; (k) Steffen A, Braun T, Neumann B and Stammler H-G 2007Angew. Chem., Int. Ed. 468674

7. (a) Fujita M, Sasaki O, Mitsuhashi T, Fujita T, Yazaki J, Yamaguchi K and Ogura K 1996 Chem. Commun. 1535; (b) Diaz P, Tovilla J A , Ballester P, Benet- Buchholz J and Vilar R 2007 Dalton Trans. 3516. (c) Ghosh S and Mukherjee P S 2009 Inorg. Chem. 48 2605. (d) Ma G, Jung YS, Chung D S and Hong J-I 1999 Tetrahedron Lett. 40 531; (e) Ferrer M, Gutierrez A, Mounir M, Rossell O, Ruiz E, Rang A and Engeser M 2007 Inorg. Chem. 46 3395

8. (a) Wimmer S and Castan P 1989 J. Chem. Soc., Dalton Trans. 403; (b) Drew H D K, Pinkard, F W, Preston G H and Wardlaw W 1932 J. Chem. Soc. 1895

9. Sheldrick G M 2013 SHELXL 2013, University of Göttingen, Germany 
10. (a) Yu S-Y, Jiao Q, Li S-H, Huang H-P, Li Y-Z, Pan Y-J, Sei Y and Yamaguchi K 2007 Org. Lett. 9 1379; (b) Yu S-Y, Huang H-P, Li S-H, Jiao Q, Li Y-Z, Wu B, Sei Y, Yamaguchi K, Pan Y-J and Ma H-W Inorg. Chem.
200544 9471; (c) Steffen A, Braun T, Neumann B and Stammler H-G 2007 Angew. Chem., Int. Ed. 1198828

11. Lai S-W, Chan M C-W, Peng S-M and Che C-M 1999 Angew. Chem., Int. Ed. 38669 